\title{
Modeling and Numerical Simulation of Hydrogen Production from Dimethyl Ether Steam Reforming
}

\author{
Lei Guo, Cong Li \\ Automotive Engineering College, Shanghai University Of Engineering Science, Shanghai, China \\ Email: 939889358@qq.com
}

How to cite this paper: Guo, L. and Li, C. (2018) Modeling and Numerical Simulation of Hydrogen Production from Dimethyl Ether Steam Reforming. Open Access Library Journal, 5: e4531. https://doi.org/10.4236/oalib.1104531

Received: March 20, 2018

Accepted: May 22, 2018

Published: May 25, 2018

Copyright $\odot 2018$ by authors and Open Access Library Inc.

This work is licensed under the Creative Commons Attribution International License (CC BY 4.0).

http://creativecommons.org/licenses/by/4.0/

\section{(c) (i) Open Access}

\begin{abstract}
In order to study the steam reforming process of dimethyl ether, a kind of reformer reactor with thermal jacket, heat pipe and catalytic reaction bed was designed. The effects of reaction gas temperature, molar ratio of water to ether and the structure parameters of the reactor on the conversion of dimethyl ether, the yield of hydrogen, the hydrogen concentration at the outlet of the reactor and the concentration of $\mathrm{CO}_{2}$ were investigated experimentally. The mathematics and power of the reactor were established Learn model The COMSOL software was used to simulate it. The simulation results showed the temperature distribution, mass distribution, DME conversion and hydrogen production in DME steam reforming process. These simulation results will provide useful data for the design and operation of small scale catalytic reforming bed reactors.
\end{abstract}

\section{Subject Areas \\ Mechanical Engineering}

\section{Keywords}

Dimethyl Ether Steam Reforming, Hydrogen Production, Kinetics

\section{Introduction}

With the rapid development of the world economy and the continuous improvement of the appointed living standard, the consumption of primary energy has rapidly risen. Oil is still the world's leading fuel. The consumption of oil will inevitably bring many new challenges to the growth of the world economy, energy security and climate change. Therefore, the search for a new clean alter- 
native energy is very necessary. As discussed by Chaubey et al. [1], hydrogen, as a clean renewable energy source, has the characteristics of storage and transport, attracting the attention of all countries in the world and being considered as the most promising new energy source in the 21 st century.

As discussed by Alves et al. [2], hydrogen fuel cell technology has long been considered as one of the ultimate solutions to harness the power of hydrogen to solve future human energy crises. At present, methane (natural gas) and methanol are the most suitable raw materials for hydrogen production on a small scale. However, these materials have some defects in the reforming and hydrogen production. For example, the methane reforming hydrogen production needs a higher temperature, and the methanol, the specific energy density is not very good, there is a certain degree of toxicity. In recent years, people are trying to explore new raw materials for hydrogen production, including bioethanol. However, dimethyl ether has attracted the attention of domestic and foreign researchers due to its unique source reliability and safety of storage and transportation as discussed by elsewhere [3] [4].

Dimethyl ether as a reforming hydrogen source has many advantages, mainly in the following four points: 1) a wide range of sources of dimethyl ether, a new synthesis of dimethyl ether to ensure the economy of the source, is conducive to large-scale application; 2) dimethyl ether is non-toxic, non-corrosive, non-trigeminy (teratogenic, carcinogenic, mutagenic) and has no damage to the atmospheric ozone layer and is easily degraded in the troposphere, thus ensuring the utilization of dimethyl ether; 3) the physical properties of DME are similar to those of liquefied petroleum gas and natural gas, and the infrastructure can be compatible with it. As a result, the commercialization cost of dimethyl ether reforming hydrogen production is greatly reduced, meanwhile, it is also reduced This new fuel into the energy market threshold as discussed by elsewhere [5] [6]; 4) As discussed by Tsolakis et al. [7], dimethyl ether (DME) liquefaction, usually in the form of liquefied gas storage, to ensure the convenience and economy of the transport process.

In this paper, the kinetics of the reaction rate of dimethyl ether reforming to hydrogen was studied. A monolithic channel reactor model was designed and its reaction process and operating parameters were simulated by COMSOL software. Water ether ratio and different reaction temperature on its hydrogen yield.

\section{Model Definition}

\subsection{Model Introduction}

\subsubsection{Model Geometry}

Figure 1 shows the microreactor geometry model structure designed by COMSOL simulation software. The microreactor consists of a heat pipe, a porous catalytic reaction bed and a heat-insulating jacket. The length of the reactor porous zone is $150 \mathrm{~mm}$, the radius is $33 \mathrm{~mm}$, the thickness of the heat-insulating jacket is $3 \mathrm{~mm}$, the radius of each tube is $4 \mathrm{~mm}$, the maximum element size is 


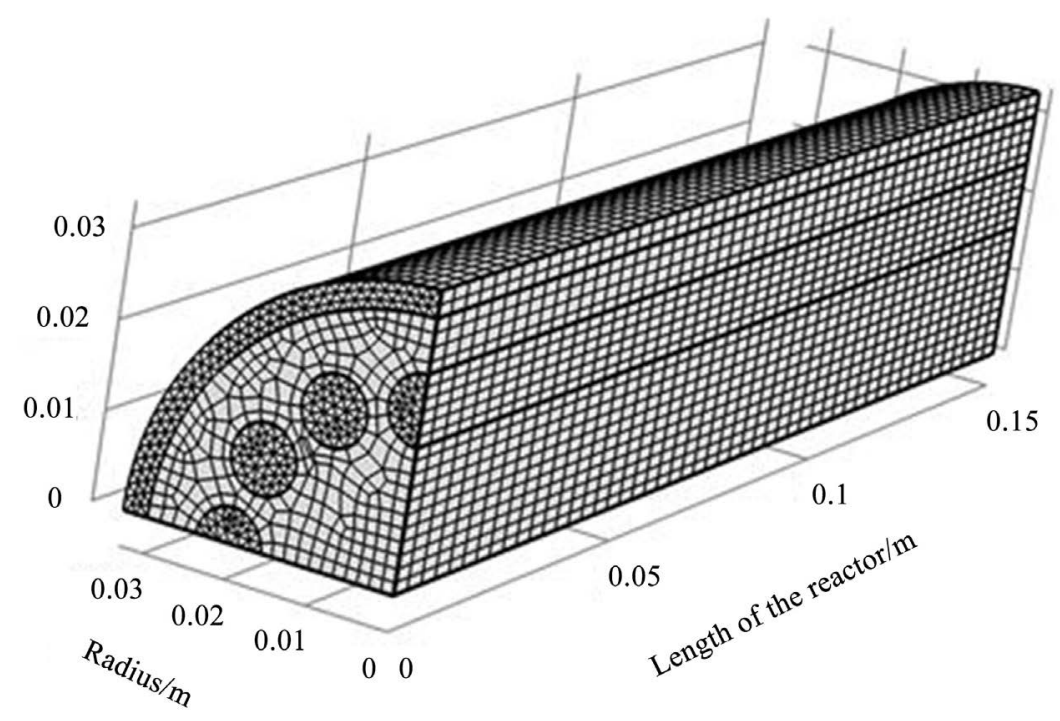

Figure 1. Reactor structure and mesh size.

$150 \mathrm{~mm}$ and the minimum element size is $7.5 \mathrm{~mm}$. The gas phase in the wall is described by the non-slip boundary conditions. The reactants flow in from the reactor inlet and carry out the reforming and hydrogen production of dimethyl ether in a packed bed of a catalyst porous catalytic reaction bed.

\subsubsection{Numerical Model and Control Equations}

The numerical simulation of DME reforming in COMSOL software is solved by the energy conservation control equation. The energy equation describes the temperature of the reaction gas in the reactor, as well as the thermal conductivity of the entire structure. Since temperature affects not only the reaction kinetics, but also the density and viscosity of the reactant gases, the energy equation is the reason that the heat pipes in the reactor structure are actually connected into a three-dimensional model.

In this reactor, the composition of the mixed gas is mainly composed of DME, $\mathrm{H}_{2} \mathrm{O}, \mathrm{CO}_{2}, \mathrm{H}_{2}$ and $\mathrm{CO}$. In addition, the volume flow is in the axial direction, whereas the mass transfer occurs predominantly in the lateral direction of the reactor wall. Therefore, the three-dimensional model is sufficient to deal with the reforming reaction.

The basic assumptions for this model are as follows:

1) the reactant gas forms a perfectly hypothetical laminar flow in the channel such that the average flow field proportionally crosses the pressure differential across the reactor;

2) the reaction rate is linear;

3) the gas flow in the direction of the channel to transmit the quality and energy only;

4) the reaction gas is incompressible, the ideal gas;

5) the reaction process is divided into three steps: dimethyl ether hydrolysis, methanol steam reforming and water gas shift reaction. 
Assuming steady state, the mass balance equation for a plug flow reactor is:

$$
\frac{\mathrm{d} F_{i}}{\mathrm{~d} V}=R_{i}
$$

where $F_{i}$ is the species molar flow rate $(\mathrm{mol} / \mathrm{s}), V$ represents the reactor volume $\left(\mathrm{m}^{3}\right)$, and is $R_{i}$ the species net reaction rate $\left(\mathrm{mol} /\left(\mathrm{m}^{3} \cdot \mathrm{s}\right)\right)$. The molar flow rate is related to the species concentrations, $c_{i}\left(\mathrm{~mol} / \mathrm{m}^{3}\right)$, through the volumetric flow rate, $V\left(\mathrm{~m}^{3} / \mathrm{s}\right)$ :

$$
F_{i}=v c_{i}
$$

where the volumetric flow rate is given by the average flow velocity, $u$ (SI unit: $\mathrm{m} / \mathrm{s})$, multiplied by the reactor cross-section $A\left(\mathrm{~m}^{2}\right)$ :

$$
v=u A
$$

The energy balance for the ideal reacting gas is:

$$
\sum_{i} F_{i} C_{p, i} \frac{\mathrm{d} T}{\mathrm{~d} V}=Q_{e x t}+Q
$$

where $C_{p, i}$ is the species molar heat capacity $(\mathrm{J} /(\mathrm{mol} \cdot \mathrm{K}))$, and $Q_{\text {ext }}$ is the heat added to the system per unit volume $\left(\mathrm{J} /\left(\mathrm{m}^{3} \cdot \mathrm{s}\right)\right)$. $Q$ denotes the heat due to chemical reaction $\left(\mathrm{J} /\left(\mathrm{m}^{3} \cdot \mathrm{s}\right)\right)$.

$$
Q=-\sum_{i} H_{j} r_{j}
$$

where $H_{j}$ the heat of reaction $(\mathrm{J} / \mathrm{mol})$, and $r_{j}$ the reaction rate $\left(\mathrm{mol} /\left(\mathrm{m}^{3} \cdot \mathrm{s}\right)\right)$.

\subsubsection{Boundary Condition}

Species concentrations are defined at the reactor inlet boundaries:

$$
c=c_{\text {in }}
$$

At the outlet, use the Outflow condition:

$$
n \cdot(-D \nabla c)=0
$$

For the heat pipe in the reactor, heat can only be conducted by conduction:

$$
-\nabla \cdot\left(k_{s} \nabla T\right)=0
$$

where $k_{s}(\mathrm{~W} /(\mathrm{m} \cdot \mathrm{K}))$ denotes the thermal conductivity of the heat pipe.

The temperature is specified at the reactor inlet boundaries:

$$
T=T_{0}
$$

At the outlet, use the Outflow condition:

$$
n \cdot(k \nabla T)=0
$$

\subsection{Chemical Reaction Kinetic Model}

DME steam reforming process is more complicated, this paper mainly studied three dimethyl ether hydrolysis, methanol steam reforming and water gas shift three reactions as discussed by Feng et al. [8], the reaction equation is as follows:

DME hydrolysis reaction:

$$
\mathrm{CH}_{3} \mathrm{OCH}_{3}+\mathrm{H}_{2} \mathrm{O}(\mathrm{g}) \Leftrightarrow 2 \mathrm{CH}_{3} \mathrm{OH} \quad \Delta H=36.6 \mathrm{~kJ} / \mathrm{mol}
$$


$\mathrm{MeOH}$ steam reforming reaction:

$$
\mathrm{CH}_{3} \mathrm{OH}+\mathrm{H}_{2} \mathrm{O} \Leftrightarrow \mathrm{CO}_{2}+3 \mathrm{H}_{2} \quad \Delta H=49.1 \mathrm{~kJ} / \mathrm{mol}
$$

Water gas shift reaction:

$$
\mathrm{CO}+\mathrm{H}_{2} \mathrm{O} \Leftrightarrow \mathrm{CO}_{2}+\mathrm{H}_{2} \quad \Delta H=-47.17 \mathrm{~kJ} / \mathrm{mol}
$$

The total reaction is:

$$
\mathrm{CH}_{3} \mathrm{OCH}_{3}+3 \mathrm{H}_{2} \mathrm{O}(\mathrm{g}) \Leftrightarrow 2 \mathrm{CO}_{2}+6 \mathrm{H}_{2} \quad \Delta H=+135 \mathrm{~kJ} / \mathrm{mol}
$$

For the above reaction of dimethyl ether reformer hydrogenation, the reaction kinetic rate equation can draw as discussed by Oar-Arteta et al. [9]:

$$
\begin{gathered}
r_{H}=\frac{K_{H} K_{M D, a} K_{W, a}\left(P_{D} P_{W}-P_{M}^{2} / K_{H}\right)}{\left(1+K_{M D, a}\left(P_{M}+P_{D}\right)+K_{W, a} P_{W}\right)^{2}} \\
r_{S R}=\frac{K_{S R} K_{M, m} K_{W, m}\left(P_{D} P_{W}-\left(P_{C O_{2}} P_{H_{2}}^{3} / K_{S R}\right)\right)}{1+K_{M, m} P_{M}+K_{W, m} P_{W}} \\
r_{r W G S}=\frac{K_{r W G S}\left(P_{C O_{2}} P_{H_{2}}-\left(P_{C O} P_{W} / K_{r W G S}\right)\right)}{1+K_{M, m} P_{M}+K_{W, m} P_{W}}
\end{gathered}
$$

In the above three formulas, $K_{M D, a}, K_{M, m}$ respectively, the adsorption constants of the oxidant $(\mathrm{MeOH}+\mathrm{DME})$ at the acidic sites and the methanol sites at the metal sites, $K_{W, a}, K_{W, m}$ represent the adsorption constants of water at the acidic site and the metal site, $P$ represent the partial pressure of the chemical substances, $K_{H}, K_{S R}, K_{r W G S}$ represent are DME hydrolysis, methanol steam reforming and water gas shift reaction equilibrium constant. Table 1 demonstrates the kinetic parameters. The reaction rate in (15) (16) (17) can be obtained from the data in the table.

\section{Simulation Results and Analysis}

Selected kinetic models have been used to model the reactor. Simulation allows the determination of a suitable range of operating conditions (temperature, reactor length and S/DME ratio) resulting in high $\mathrm{H}_{2}$ and low $\mathrm{CO}$ yields. The calculated reaction equation is as follows:

Dimethyl ether conversion:

$$
X_{D M E}=\frac{F_{D M E, \text { in }}-F_{D M E, \text { out }}}{F_{D M E, \text { in }}} \times 100 \%
$$

Yields of Hydrogen:

$$
Y=\frac{F_{i}}{F_{0} \cdot v_{i}}
$$

where $F_{D M E, \text { in }}, F_{D M E, \text { out }}$ denote the molar flow rate of DME at the inlet and outlet of the reactor and $F_{i}$ denote the molar flow rate of each product $\left(\mathrm{H}_{2}, \mathrm{CO}_{2}\right)$ at the outlet of the reactor, which $v_{i}$ is the stoichiometric coefficient of formation of component $\mathrm{i}$ from methanol, $\mathrm{CO}_{2}$ is $2, \mathrm{H}_{2}$ is 6 . 
Table 1. DME hydrolysis, methanol steam reforming, water vapor shift reaction kinetics parameters.

\begin{tabular}{ccc}
\hline parameter & $\mathrm{K}(623 \mathrm{~K})$ & activation energy \\
\hline$K_{H}$ & $3.26( \pm 1.31)\left(\mathrm{g}_{\text {catalyst }} \mathrm{h} \mathrm{atm}\right)^{-1}$ & $145.1( \pm 33.7) \mathrm{KJ} / \mathrm{mol}$ \\
$K_{S R}$ & $15.2( \pm 4.30)\left(\mathrm{g}_{\text {catalyst }} \mathrm{h} \mathrm{atm}\right)^{-1}$ & $28.9( \pm 8.41) \mathrm{KJ} / \mathrm{mol}$ \\
$K_{r W G S}$ & $20.1( \pm 6.7)\left(\mathrm{g}_{\text {catalyst }} \mathrm{h} \mathrm{atm}\right)^{-1}$ & $63.3( \pm 18.4) \mathrm{KJ} / \mathrm{mol}$ \\
$K_{M D, a}$ & $1.67( \pm 0.42) \mathrm{atm}^{-1}$ & $24.5( \pm 8.11) \mathrm{KJ} / \mathrm{mol}$ \\
$K_{M, m}$ & $31.46( \pm 0.37) \mathrm{atm}^{-1}$ & $40.2( \pm 10.7) \mathrm{KJ} / \mathrm{mol}$ \\
$K_{W, a}$ & $6.15( \pm 1.89) \mathrm{atm}^{-1}$ & $55.8( \pm 18.4) \mathrm{KJ} / \mathrm{mol}$ \\
$K_{W, m}$ & $5.81( \pm 2.04) \mathrm{atm}^{-1}$ & $33.7( \pm 8.11) \mathrm{KJ} / \mathrm{mol}$ \\
\hline
\end{tabular}

\subsection{Effect of Reactor Geometric Parameters on Reaction}

Figure 2 shows the reactor temperature distribution. The axial length of the reactor was chosen to study the effect of geometric parameters. In all simulation simulations, the ratio of DME to steam is 1:3, and the energy exchange between the heating tube and the reforming bed is clearly shown in Figure 2. Gas from the heating tube enters at $753 \mathrm{~K}$ and leaves at about $565 \mathrm{~K}$ due to conduction to the porous area. At the same time, the reformer gas temperature inlet $553 \mathrm{~K}$, the final average temperature of $699 \mathrm{~K}$ is due to endothermic steam reforming reaction of dimethyl ether, resulting in the temperature began to decrease. As the reaction rate decreases with decreasing temperature and DME content, the energy supplied by the heating tube increases with reactor length.

Figure 3 shows the distribution of the mass fraction of all the reactants in the reactor with the axial length of the reactor. It can be seen from the figure that the length of the entire catalytic reaction bed is a positive conversion DME. It can be seen from the product distribution results that the volume contents of DME, steam, $\mathrm{H}_{2}$ and $\mathrm{CO}_{2}$ are respectively the function of the axial length of the processor. The volumetric contents of $\mathrm{H} 2$ and $\mathrm{CO}_{2}$ increase rapidly while the DME and water vapor gradually decrease along the length of the reaction bed due to the fast reaction of DME and higher vapor concentrations near the reactor inlet.

Figure 4 shows the DME concentration distribution along the axial length of the reactor. It is clear from the figure that since the local reaction is mainly temperature controlled, the heat provided by the tube is sufficient to effectively utilize the entire catalytic bed. In the vicinity of the heating tube and catalyst bed, as the reaction progresses, the DME mass fraction gradually decreases along the axial length. This is because dimethyl ether endothermic hydrolysis reaction, the lower the temperature resulting in a higher conversion of dimethyl ether.

\subsection{Effect of Inlet Temperature}

The reaction conditions for the water ether molar ratio of 3, Figure 5 and Figure 6 , respectively, dimethyl ether conversion and hydrogen yield at different inlet 


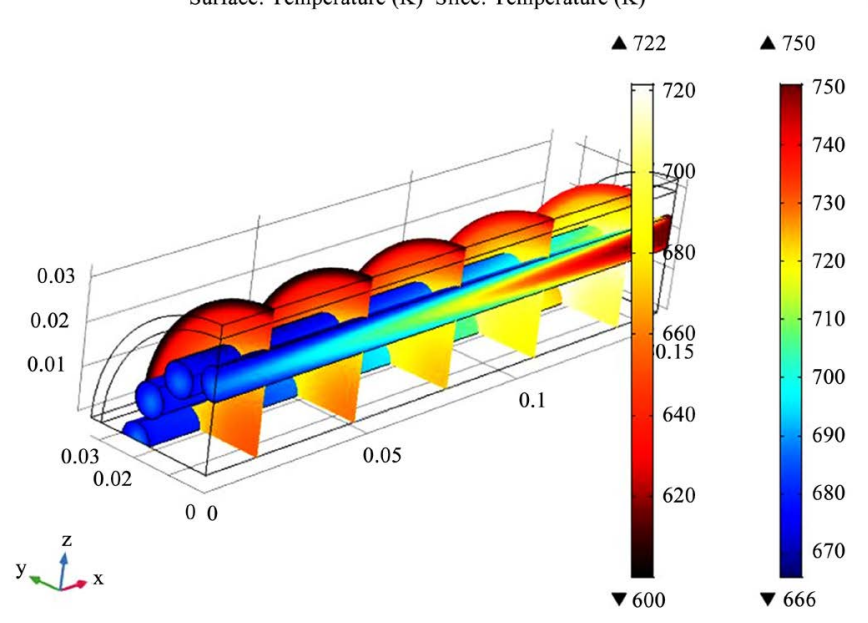

Figure 2. Reactor temperature distributions.

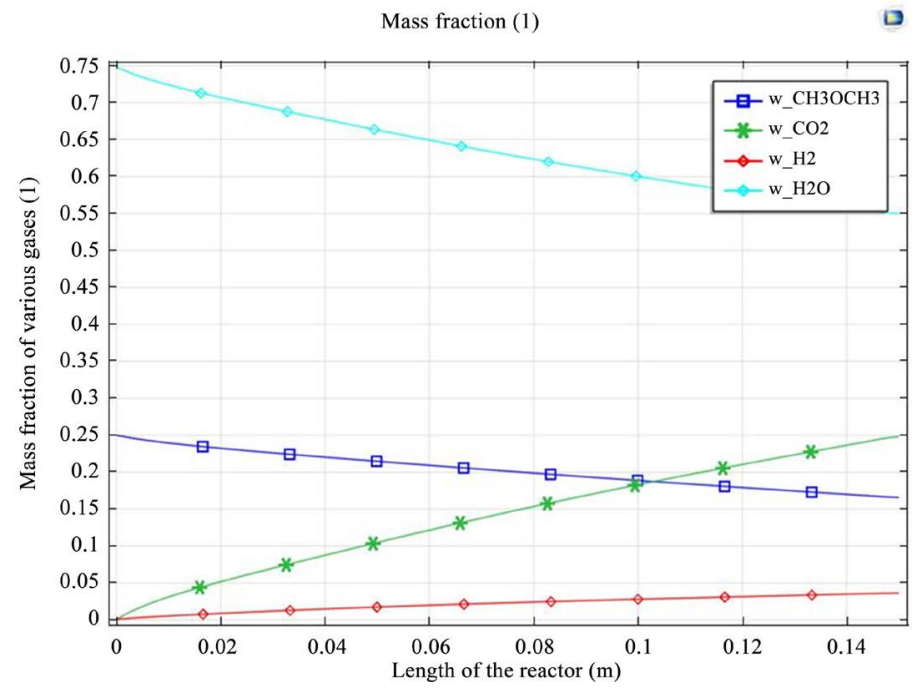

Figure 3. Mass fraction distribution of reacting species.

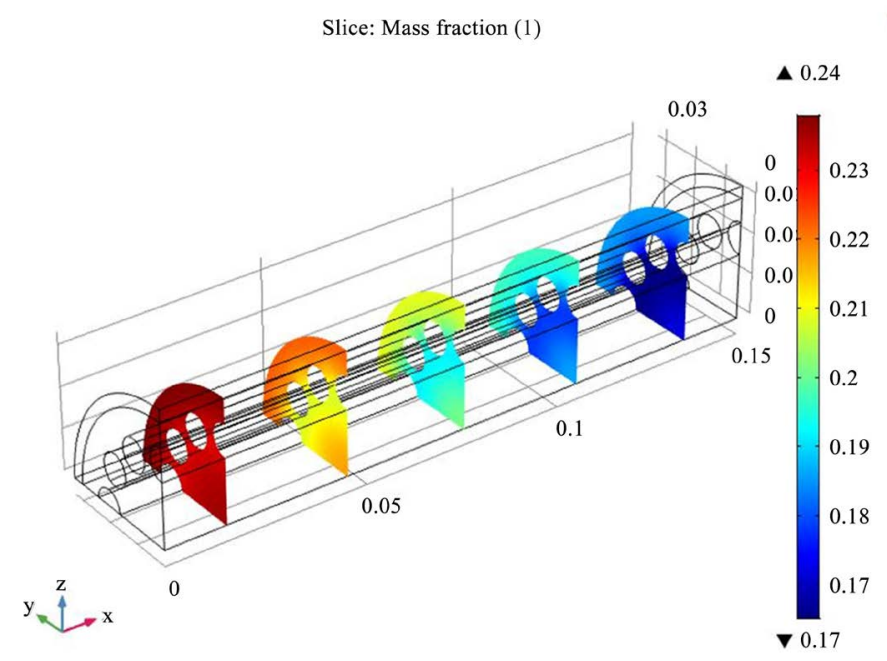

Figure 4. Concentration distribution of DME in the reformer bed. 


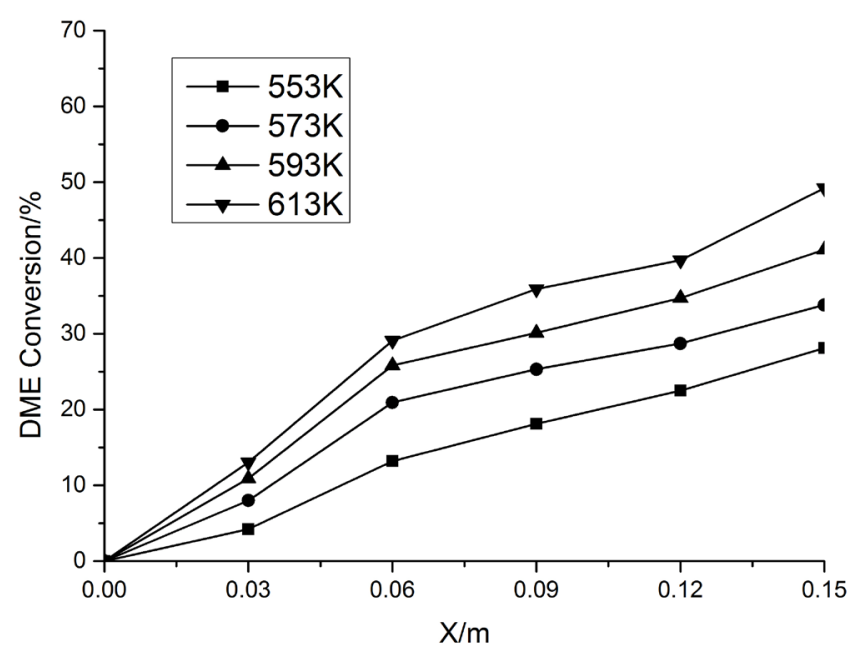

Figure 5. DME conversion at the reactor axial length.

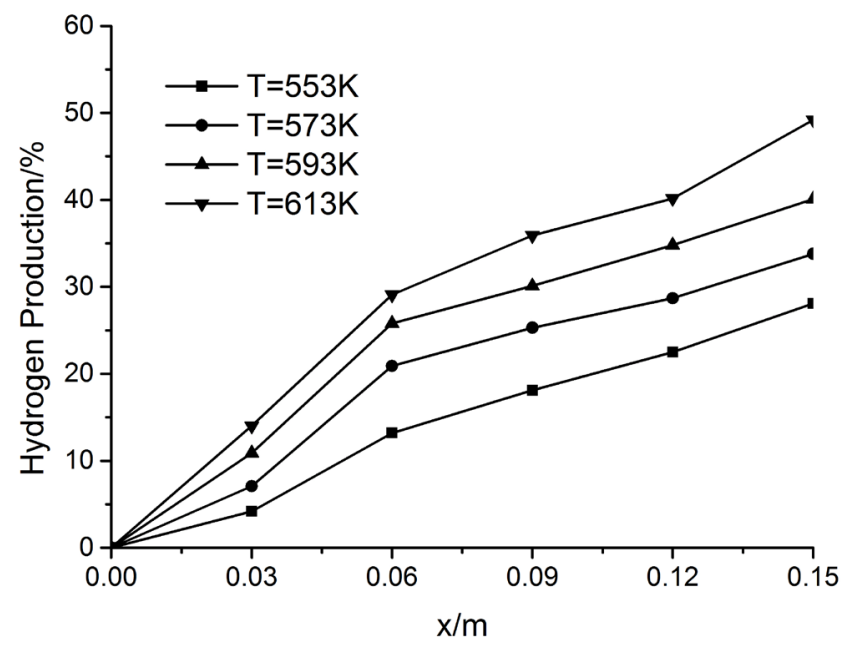

Figure 6. Hydrogen production rate at reactor axial length.

temperature changes. Change the temperature values were $553 \mathrm{~K}, 573 \mathrm{~K}, 593 \mathrm{~K}$, $613 \mathrm{~K}$. It can be seen from Figure 5 that with the increase of temperature at the inlet of the material, the conversion of dimethyl ether and the yield of hydrogen are significantly increased, and the performance of the whole reaction process gets better and better with the increase of temperature. The main reaction of hydrogen generated during the steam reforming of dimethyl ether to steam is the steam reforming reaction of methanol. Since the total reaction is endothermic, the hydrogen yield increases as the temperature of the inlet of the reaction mixture increases significantly improved.

\subsection{Effect of Steam/DME Molar Ratio}

The molar ratio of steam/DME is one of the most important parameters that influence the steam reforming process. Figure 7 shows the variation of dimethyl ether reaction rate at different water-ether mole ratios at temperatures ranging from $280^{\circ} \mathrm{C}$ to $340^{\circ} \mathrm{C}$. As can be seen from the Figure 8, with the molar ratio of 


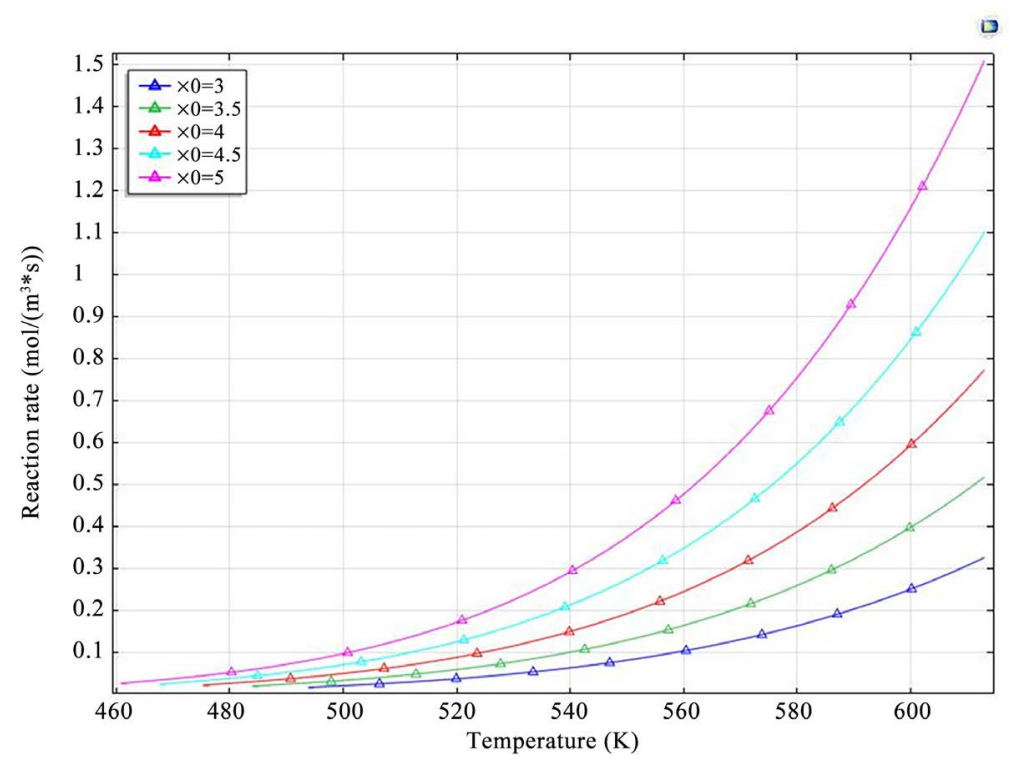

Figure 7. Different steam/DME ratio at different inlet temperature.

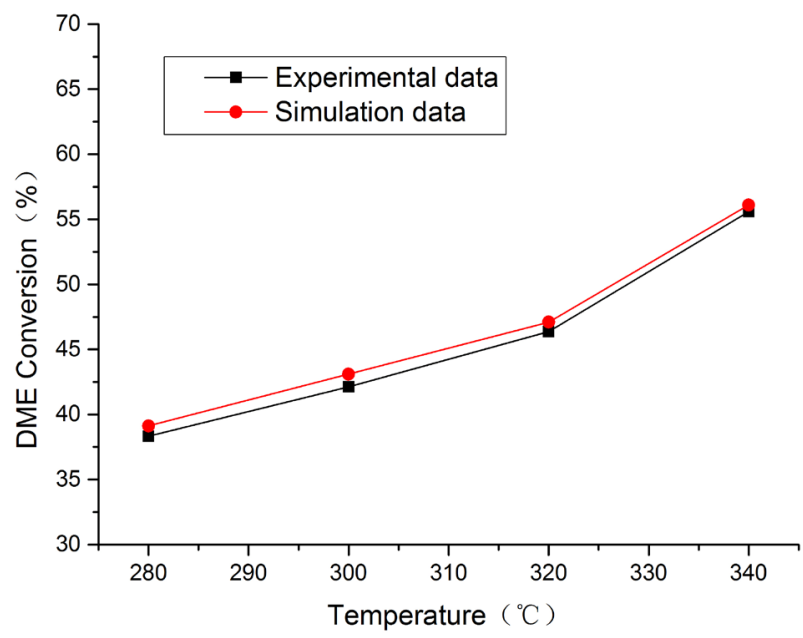

Figure 8. Comparison of experimental and simulation results on the effect of reaction temperature on DME conversion.

water ether ether of $3,3.5,4,4.5,5$, respectively, with the increasing molar ratio of water to ether and the temperature increases, dimethyl ether reforming hydrogen production reaction The reaction rate is also constantly accelerating. Similarly, we can also know that the hydrogen yield will be more and more as the reaction proceeds. Therefore, it can be inferred that excessive water and high temperature during steam reforming of DME may promote the reaction. This can also be called the concentration effect, that is, DME is a more expensive material than water vapor. In view of the reversible reaction rate and reaction conversion rate limited by the balance, in order to improve the DME utilization rate and to speed up the reaction rate, Very effective. However, it does not mean that the higher the water-to-water ratio, the better. Due to the relatively large heat capacity of water, excess water needs to consume more heat in the DME re- 
forming hydrogen production reaction. Since the entire reforming reaction is endothermic, Higher water ether ratio is not conducive to DME conversion.

\section{Validation of the Model}

Steam and DME enter the gas mixer through the mass flow controller. The mixed gas flows into the reactor containing the $\mathrm{CuO} / \mathrm{ZnO} / \mathrm{Al}_{2} \mathrm{O}_{3}+\mathrm{ZSM} 5$ catalyst. Product gas from the reactor flows into a dryer to separate the steam from the gas mixture. Finally, a portion of the gas product flows into the gas chromatograph (GC-9900) to detect the gas composition. Gas chromatograph connected to the computer, the composition of the product can be analyzed by the recorder. Thermocouples were used to measure the catalyst bed temperature in the reactor.

The experimental conditions in the reactor are exactly the same as those in the simulation. Inlet temperature is $553 \mathrm{~K}$, exhaust temperature is $753 \mathrm{~K}$. It is clear from Figure 8 and Figure 9 that the DME conversion and the $\mathrm{H}_{2}$ yield are numerically calculated to be in good agreement with the actual data. This also shows that the model in this work can be very good description of dimethyl ether reforming hydrogen reaction process.

\section{Conclusions}

In this paper, a dimethyl ether steam reforming hydrogen production reactor was established by using COMSOL software, and the reactor performance was simulated with a suitable catalyst. The effects of different temperatures, molar ratios of water to ether and reactor geometry parameters impact on the reforming reactor. Simulation model can describe the whole reaction process well, the conclusion is as follows:

1) Higher water-ether ratio can promote the forward reaction and improve the conversion of dimethyl ether.

2) As the steam reforming reaction is generally endothermic reaction, higher

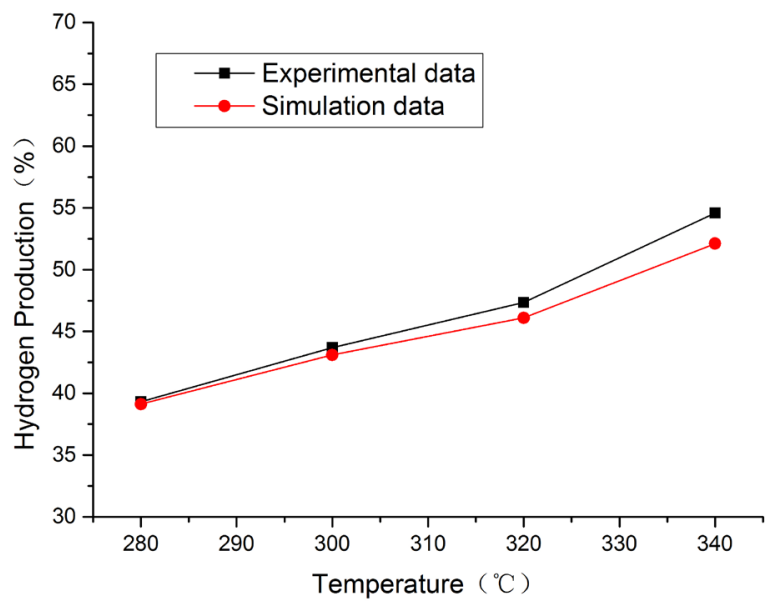

Figure 9. Comparison of experimental and simulative effects of reaction temperature on hydrogen yield. 
inlet temperature can provide more energy required for the reaction, thereby speeding up the reaction and increasing the hydrogen yield.

3) The mathematical model and physical model of the reactor can predict the performance of the reactor to a certain extent, and can improve the design of the catalytic reforming microreactor with certain reference value.

\section{Acknowledgments}

This work was supported by National Natural Science Foundation of China under Grant NO.51505275.

\section{References}

[1] Chaubey, R., Sahu, S., James, O.O. and Maity, S. (2013) A Review on Development of Industrial Processes and Emerging Techniques for Production of Hydrogen from Renewable and Sustainable Sources. Renewable \& Sustainable Energy Reviews, 23, 443-462. https://doi.org/10.1016/j.rser.2013.02.019

[2] Alves, H.J., Junior, C.B., Niklevicz, R.R., Frigo, E.P. and Frigo, M.S. (2013) Overview of Hydrogen Production Technologies from Biogas and the Applications in Fuel Cells. International Journal of Hydrogen Energy, 38, 5215-5225. https://doi.org/10.1016/j.ijhydene.2013.02.057

[3] Park, S.J., Lee, D.W., Yu, C.Y., Lee, K.Y. and Lee, K.H. (2008) Hydrogen Production from a DME Reforming-Membrane Reactor Using Stainless Steel-Supported Knudsen Membranes with High Permeability. Journal of Membrane Science, 318, 123-128. https://doi.org/10.1016/j.memsci.2008.02.036

[4] Yan, C.F., Ye, W., Guo, C.Q., Huang, S.L., Li, W.B. and Luo, W.M. (2014) Numerical Simulation and Experimental Study of Hydrogen Production from Dimethyl Ether Steam Reforming in a Micro-Reactor. International Journal of Hydrogen Energy, 39, 18642-18649. https://doi.org/10.1016/j.ijhydene.2014.02.133

[5] Yan, C.F., Hai, H., Hu, R.R., Guo, C.Q., Huang, S.L., Li, W.B. and Wen, Y. (2014) Effect of Cr Promoter on Performance of Steam Reforming of Dimethyl Ether in a Metal Foam Micro-Reactor. International Journal of Hydrogen Energy, 39, 18625-18631. https://doi.org/10.1016/j.ijhydene.2014.02.152

[6] Elewuwa, F.A. and Makkawi, Y.T. (2015) Hydrogen Production by Steam Reforming of DME in a Large Scale CFB Reactor. Part I: Computational Model and Predictions. International Journal of Hydrogen Energy, 40, 15865-15876.

https://doi.org/10.1016/j.ijhydene.2015.10.050

[7] Tsolakis, A. and Megaritis, A. (2004) Catalytic Exhaust Gas Fuel Reforming for Diesel Engines-Effects of Water Addition on Hydrogen Production and Fuel Conversion Efficiency. International Journal of Hydrogen Energy, 29, 1409-1419. https://doi.org/10.1016/j.ijhydene.2004.01.001

[8] Feng, D.M., Wang, Y.Y., Wang, D.Z., et al. (2009) Steam Reforming of Dimethyl Ether over $\mathrm{CuO}-\mathrm{ZnO}-\mathrm{Al}_{2} \mathrm{O}_{3}-\mathrm{ZrO}_{2}+\mathrm{ZSM}-5$ :A Kinetic Study. Chemical Engineering Journal, 146, 477-485. https://doi.org/10.1016/j.cej.2008.11.005

[9] Oar-Arteta, L., Aguayo, A.T., Remiro, A., et al. (2016) Kinetics of the Steam Reforming of Dimethyl Ether over $\mathrm{CuFe}_{2} \mathrm{O}_{4} / \gamma-\mathrm{Al}_{2} \mathrm{O}_{3}$. Chemical Engineering Journal, 306, 401-412. https://doi.org/10.1016/j.cej.2016.07.075 